Article

\title{
A Miniature Integrated Multimodal Sensor for Measuring pH, EC and Temperature for Precision Agriculture
}

\author{
Masato Futagawa ${ }^{1, *}$, Taichi Iwasaki ${ }^{2}$, Hiroaki Murata ${ }^{2}$, Makoto Ishida ${ }^{2,3}$ and \\ Kazuaki Sawada ${ }^{2,3,4}$
}

1 Head Office for "Tailor-Made and Baton-Zone" Graduate Course, Toyohashi University of Technology, 1-1, Hibarigaoka, Tempaku-cho, Toyohashi, Aichi 441-8580, Japan

2 Department of Electrical and Electronic Information Engineering, Toyohashi University of Technology, Aichi 441-8580, Japan; E-Mails: iwasaki-t@int.ee.tut.ac.jp (T.I.); murata-h@int.ee.tut.ac.jp (H.M.); ishida@ee.tut.ac.jp (M.I.); sawada@ee.tut.ac.jp (K.S.)

3 Electronics-Inspired Interdisciplinary Research Institute (EIIRIS), Toyohashi University of Technology, Aichi 441-8580, Japan

4 Core Research for Evolutional Science and Technology, Japan Science and Technology Agency, 7, Gobancho, Chiyoda-ku, Tokyo 102-0076, Japan

* Author to whom correspondence should be addressed; E-Mail: futagawa@batonzone.tut.ac.jp; Tel.: +81-532-44-6974; Fax: +81-532-81-5115.

Received: 30 April 2012; in revised form: 30 May 2012 / Accepted: 1 June 2012 /

Published: 15 June 2012

Abstract: Making several simultaneous measurements with different kinds of sensors at the same location in a solution is difficult because of crosstalk between the sensors. In addition, because the conditions at different locations in plant beds differ, in situ measurements in agriculture need to be done in small localized areas. We have fabricated a multimodal sensor on a small Si chip in which a $\mathrm{pH}$ sensor was integrated with electrical conductivity (EC) and temperature sensors. An ISFET with a $\mathrm{Si}_{3} \mathrm{~N}_{4}$ membrane was used for the $\mathrm{pH}$ sensor. For the EC sensor, the electrical conductivity between platinum electrodes was measured, and the temperature sensor was a p-n junction diode. These are some of the most important measurements required for controlling the conditions in plant beds. The multimodal sensor can be inserted into a plant bed for in situ monitoring. To confirm the absence of crosstalk between the sensors, we made simultaneous measurements of $\mathrm{pH}, \mathrm{EC}$, and temperature of a $\mathrm{pH}$ buffer solution in a plant bed. When the solution was diluted with hot or cold water, the real time measurements showed changes to the EC and 
temperature, but no change in $\mathrm{pH}$. We also demonstrated that our sensor was capable of simultaneous in situ measurements in rock wool without being affected by crosstalk.

Keywords: multimodal sensor; electrical conductivity sensor; $\mathrm{pH}$ sensor; temperature sensor; crosstalk; simultaneous measurement; real time measurement; rock wool; agriculture

\section{Introduction}

Performing several simultaneous measurements with different types of sensor in conducting solutions is difficult, because of the crosstalk between sensors mediated through the solution. A sensor that applies an electrical current to the solution and another that monitors voltage potential can easily affect each other. Therefore, to make simultaneous multimodal measurements at a localized point using several kinds of sensor we need to carefully consider the operating methods used in order to avoid crosstalk.

In recently years, precise control of the growth conditions for plants has become an active area of research for ensuring food safety [1,2], increasing food production [3,4], and decreasing the labor load on agricultural workers [5]. The key point to accomplish these goals is the proper use of sensors. Numerical measurements that quantify the changes to plants and the growth environment using the sensors are required. Various kinds of sensor are used in agriculture, but these sensors are insufficient for the precision control required. Especially, in situ monitoring of plant beds, such as measurements of the nutrient concentration, $\mathrm{pH}$, etc., is difficult because particle sizes and plant roots, which are with the solution, are non-uniform [6-9]. Therefore, for in situ measurements in plant beds, several different types of sensor are needed to make simultaneous measurements at the same point. In addition, the size of the sensors needs to be much smaller than the sensors currently used, which are more than a centimeter in length, in order to make observations at localized points, thereby complex changes to the various conditions at different points around the roots.

We focused on $\mathrm{pH}$, electrical conductivity (EC), and temperature sensing in soilless agriculture. These data are very important for precision agriculture [10,11]. The $\mathrm{pH}$ is controlled to prevent barrier growth. The measurement is important because the solubility of minerals in acidic and alkaline solutions is different and the solution concentration changes with solubility [12-15]. The EC is measured to obtain the ion concentration of all the species in the nutrient solution [16]. In precision agriculture, the composition ratio of the main ion species, i.e., nitrogen ions, phosphoric acid and potassium, in the nutrient solution is known by the user. Therefore, measurement of the total ion concentration is sufficient [17]. The temperature is controlled for conservation of growing temperatures of each kind of plant [18-20], and is used to make corrections to the $\mathrm{pH}$ and EC. To monitor these data in soilless rock wool, as shown in Figure 1(a), it is necessary make simultaneous measurements at the same point near roots. In addition, the sensor size should be small for insertion into the medium. In other groups, EC sensor [21,22] and $\mathrm{pH}$ sensor [23] to monitor into medium had been studied. However, there are currently no sensors available that can perform these types of measurements. 
In this study, we worked toward implementing a multimodal sensor with these three functional capabilities. This new study followed on from our previous work on a small EC sensor [24,25], which we inserted into rock wool (shown in Figure 1(b)), and an integrated EC and temperature sensor $[26,27]$ used for monitoring the health of cows.

Figure 1. Tomato plants in a soilless rock wool medium for precision agriculture. (a) Tomato plants with a dripper in each piece of rock wool; (b) An example of in situ EC monitoring in rock wool using a previous EC sensor. The sensor size could be inserted without constraint.

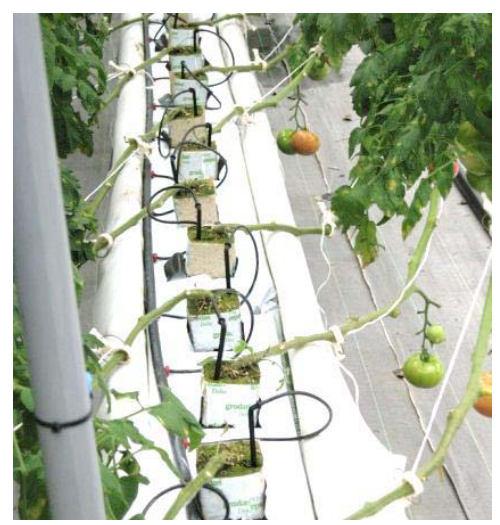

(a)

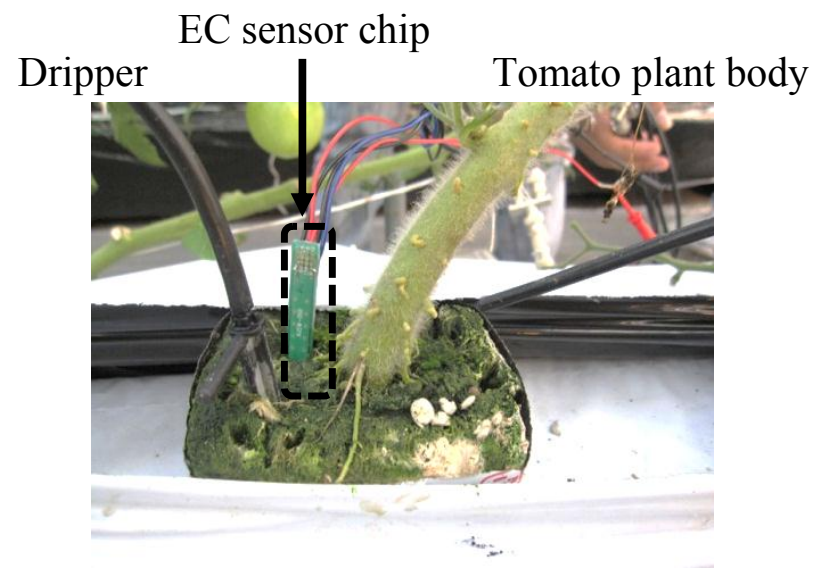

(b)

\section{Design Section}

In this section we discuss the planning and design of the sensors. In Section 2.1, the concept of this work is presented. In Sections 2.2 to 2.4 , the sensors- $\mathrm{pH}, \mathrm{EC}$, and temperature sensors-and their fundamental measurement methods are discussed. In Section 2.5, the operation of the integrated multimodal sensor is described.

\subsection{Concept of This Work}

In our previous work, we were able to insert an EC sensor chip [24] into rock wool, as shown in Figure 1(b). In this work, in situ measurements in rock wool were made. The chip size in this study was $5 \mathrm{~mm} \times 5 \mathrm{~mm}$ square which is same size as the EC sensor chip. An integrated EC and temperature sensor chip was fabricated for research in a different field [26]. This technology was used in this new study, for which multimodal sensor chips with $\mathrm{pH}, \mathrm{EC}$ and temperature sensing areas were fabricated. The $\mathrm{pH}$ sensor on our new chip uses an ion-sensitive field effect transistor (ISFET) type sensor. This type of device is compatible with Si large-scale integration (LSI) processes. Because our temperature sensors are $\mathrm{p}-\mathrm{n}$ junction diodes, these could also be fabricated with the process. The EC and $\mathrm{pH}$ sensors are required to make measurements at the same point in the solution. The temperatures of the solution, the air, the culture medium and so on also have to be monitored. Therefore, the placement of the sensor areas on the chip is an important design consideration. This placement is described in Section 3. 


\section{2. $\mathrm{pH}$ Sensor}

The $\mathrm{pH}$ sensors fabricated using Si LSI process are mainly ISFETs [28,29] or sensors using charge transfer technology [30]. For simultaneously sensing $\mathrm{pH}$ and EC, an ISFET type $\mathrm{pH}$ sensor which can operate continuously was selected. To eliminate crosstalk it was necessary to use a band pass filter. This is discussed in Section 4. In addition, the operation is simple and miniaturization is easy.

The voltage potential $\varphi_{c h}$ of a sensing membrane in an aqueous solution obeys the Nernst equation, which is given by Equation (1) with respect to $\mathrm{H}^{+} / \mathrm{OH}^{-}$ions [31]:

$$
\varphi_{c h}=V_{R E F}+\frac{R T}{F} \ln \alpha_{H}
$$

where $F$ is the Faraday constant, $R$ is the gas constant, $T$ is the absolute temperature, $V_{R E F}$ is the potential of the reference electrode, and $\alpha_{H}$ is the active ion ratio of hydrogen to hydroxide. The term $\varphi_{c h}$ is a direct current (DC) signal. This is a key point for simultaneous measurements with an EC sensor, since the EC sensor operates with an alternating current (AC) signal at $10 \mathrm{kHz}$. However, because the EC signal appears in $V_{R E F}$ as flicker noise, simultaneous measurements are not easy to do. Nevertheless, this problem can be solved. Several kinds of membrane material have been used [32] such as $\mathrm{Si}_{3} \mathrm{~N}_{4}, \mathrm{Ta}_{2} \mathrm{O}_{5}, \mathrm{Al}_{2} \mathrm{O}_{3}, \mathrm{SiO}_{2}$, and so on. The membrane is required to be highly non-permeable. In this study, $\mathrm{Si}_{3} \mathrm{~N}_{4}$ was used because it is non-permeable and is compatible with Si LSI processes.

\subsection{EC Sensor}

The EC sensor uses platinum electrodes, which we have studied in previous work [24]. The sensor measures the conductivity of the solution, which gives the ion concentration of the nutrient solution in between the electrodes. Because platinum is chemically stable, long term monitoring for over 1.5 years using our EC sensor has been achieved [8]. The sensor operates at $10 \mathrm{kHz}$ sine wave in order to minimize the impedance of the electric double layer which has a capacitance of about $1 \mu \mathrm{F}$. The EC sensor applies a voltage to the solution, and the $\mathrm{pH}$ sensor monitors the potential of the sensing membrane. In addition, the potential window of platinum for which no oxidation or reduction occurs is from about +0.5 to $-0.5 \mathrm{~V} v$ s. SCE with $\mathrm{pH}$ from 0 to 14 [33]. Taking this into consideration, the EC sensor was operated with voltage amplitude of 0.25 volts and a DC offset of 0 volts.

\subsection{Temperature Sensor}

We fabricated a sensor with temperature and EC sensing areas for monitoring the health of cows in previous work [26]. The temperature sensor was a p-n junction diode which could be fabricated together with the ISFET using Si LSI technology. The forward current of a p-n junction diode is given approximately by Equation (2) [34]:

$$
I_{F}=I_{0}\left\{\exp \left(\frac{q V_{F}}{n k T}\right)-1\right\}
$$

where $I_{F}$ is the forward current, $V_{F}$ is the forward voltage, $I_{0}$ is reverse saturation current, $k$ is the Boltzmann constant, $T$ is absolute temperature, $q$ is the electronic charge, and $n$ has a value between 1 and 2. 
When a constant current is applied to a p-n junction temperature sensor, Equation (2) can be rearranged as follows:

$$
V_{F}=\frac{n k T}{q} \cdot \ln \left(\frac{I_{F}}{I_{0}}+1\right) \propto T
$$

Thus, the output voltage $V_{F}$ varies linearly with temperature. The top passivation layers (SiOx and $\mathrm{SiN}$ ) were used to isolate the temperature sensor from the solution. The sensor was surrounded by a p-type diffusion layer in order to isolate and shield it from noise arising from changes in the potential of the $\mathrm{pH}$ sensor, leakage current from the EC sensor and other external sources. Figure 2 shows that, without shielding, the sensor is affected by changes in the $\mathrm{pH}$ signal. When the $\mathrm{pH}$ signal changes, the temperature signal also changes by it. Therefore, the shielding layer is needed to stabilize the sensor potential for simultaneous measurements, because the sensitivity of the temperature sensor is only small (about $1 \mathrm{mV} /{ }^{\circ} \mathrm{C}$ ).

Figure 2. Diode signal affected by changes in the $\mathrm{pH}$ signal without a layer shielding the diode.

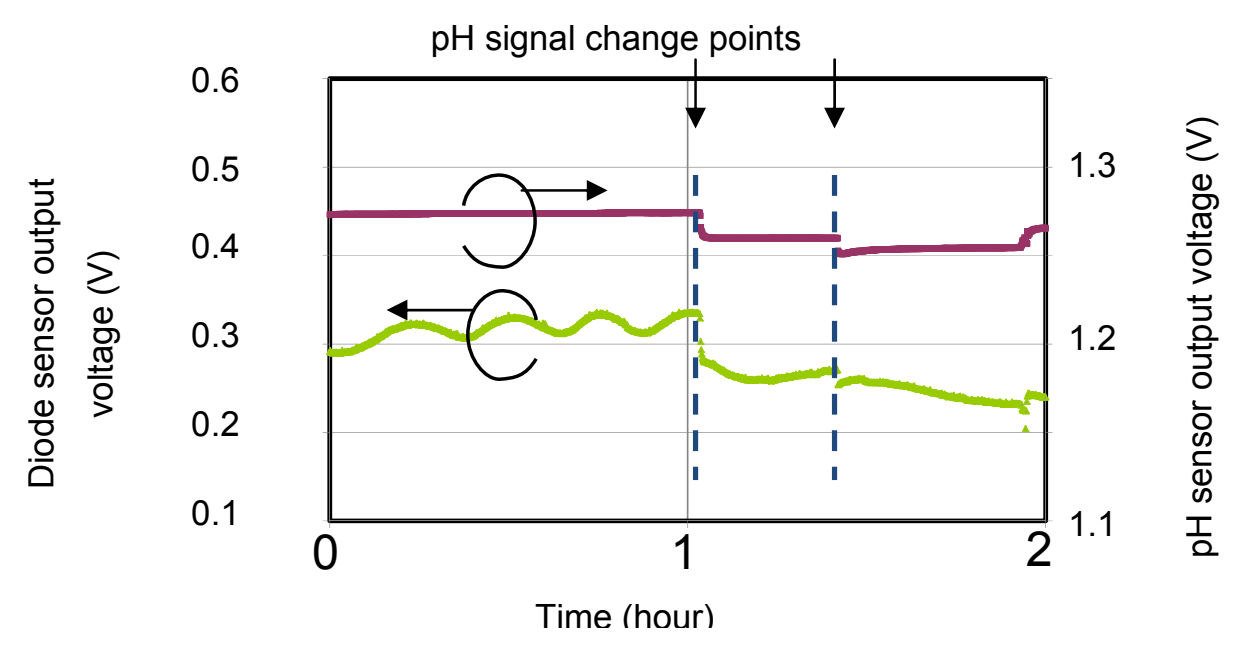

\subsection{Multimodal Sensor}

In Sections 2.2 to 2.4 we described the characteristics of each sensor and their limitations. The operating conditions for the integrated multimodal sensor are based on these, and are shown in Table 1.

Table 1. Operating conditions for $\mathrm{pH}, \mathrm{EC}$ and temperature sensing areas.

\begin{tabular}{lllll}
\hline Characteristics of Signal & $\begin{array}{l}\text { EC Sensor } \\
\text { (Pt electrodes) }\end{array}$ & $\begin{array}{l}\text { pH sensor } \\
\text { (Depletion Type ISFET) }\end{array}$ & $\begin{array}{l}\text { Temperature } \\
\text { Sensor(p-n } \\
\text { Junction Diode) }\end{array}$ \\
\hline $\begin{array}{l}\text { Electrical } \\
\text { power supply } \\
\text { to sensor }\end{array}$ & DC phase & $0 \mathrm{~V}$ & $\begin{array}{l}\text { Constant voltage for source } \\
\text { (Extra supply: Reference } \\
\text { voltage should be } 0 \mathrm{~V})\end{array}$ & Constant current \\
\hline $\begin{array}{l}\text { Output signal } \\
\text { from sensor }\end{array}$ & AC phase & $\begin{array}{l}10 \mathrm{kHz} \text { sine wave } \\
(\text { Amplitude: } 0.25 \mathrm{~V})\end{array}$ & - & - \\
\hline
\end{tabular}


The EC sensor operates at an $\mathrm{AC}$ voltage of $0.25 \mathrm{~V}$ at $10 \mathrm{kHz}$ with a zero bias offset, because the voltage should be within the range of the potential window. The $\mathrm{pH}$ sensor uses constant voltages for power and for the reference voltage, $V_{R E F}$, given in Equation (1). The reference voltage sets the $\mathrm{pH}$ sensor operating point by controlling the solution voltage. The $\mathrm{pH}$ sensor was designed as a depletion type ISFET which can be operated at zero bias, so that it would not have an impact on the offset bias of the EC sensor. In addition, for the medium culture and soil are almost ground level zero volts, the zero bias operation are important to in situ measurement.

In another point, $\mathrm{DC}$ output signal of the $\mathrm{pH}$ sensor is affected by the $\mathrm{AC}$ voltage supplied to the EC sensor. However, the AC signal affects only $V_{R E F}$, not $\alpha_{H}$. Therefore, this crosstalk can be removed by using a band pass filter because the $\mathrm{EC}$ voltage is $\mathrm{AC}$ and the $\mathrm{pH}$ signal is $\mathrm{DC}$. So, the output signal of the $\mathrm{pH}$ sensor is filtered to remove crosstalk. The result of using the filter is shown in Section 4.

\section{Fabrication of a Multimodal Sensor Chip and Signal Processing Circuit Module}

In this section we describe the structure of the sensor chip and the signal processing circuit module. In Section 3.1, we describe the integrated multimodal sensor chip, incorporating $\mathrm{pH}, \mathrm{EC}$ and temperature sensing areas. In Section 3.2, the architecture of the module is explained.

\subsection{The Integrated Multimodal Sensor Chip}

Figure 3 shows a photograph of the $5 \mathrm{~mm} \times 5 \mathrm{~mm}$ multimodal sensor chip. The integrated chip with $\mathrm{pH}, \mathrm{EC}$ and temperature sensing areas was successfully fabricated using a Si LSI process. The $\mathrm{pH}$ and temperature sensing areas are between the electrodes of the EC sensing area. The area is too small for medium culture. So the sensor can monitor $\mathrm{pH}, \mathrm{EC}$ and temperature almost at the same point in agriculture.

Figure 3. Photograph of an integrated multimodal sensor chip with $\mathrm{pH}, \mathrm{EC}$, and temperature sensing areas.

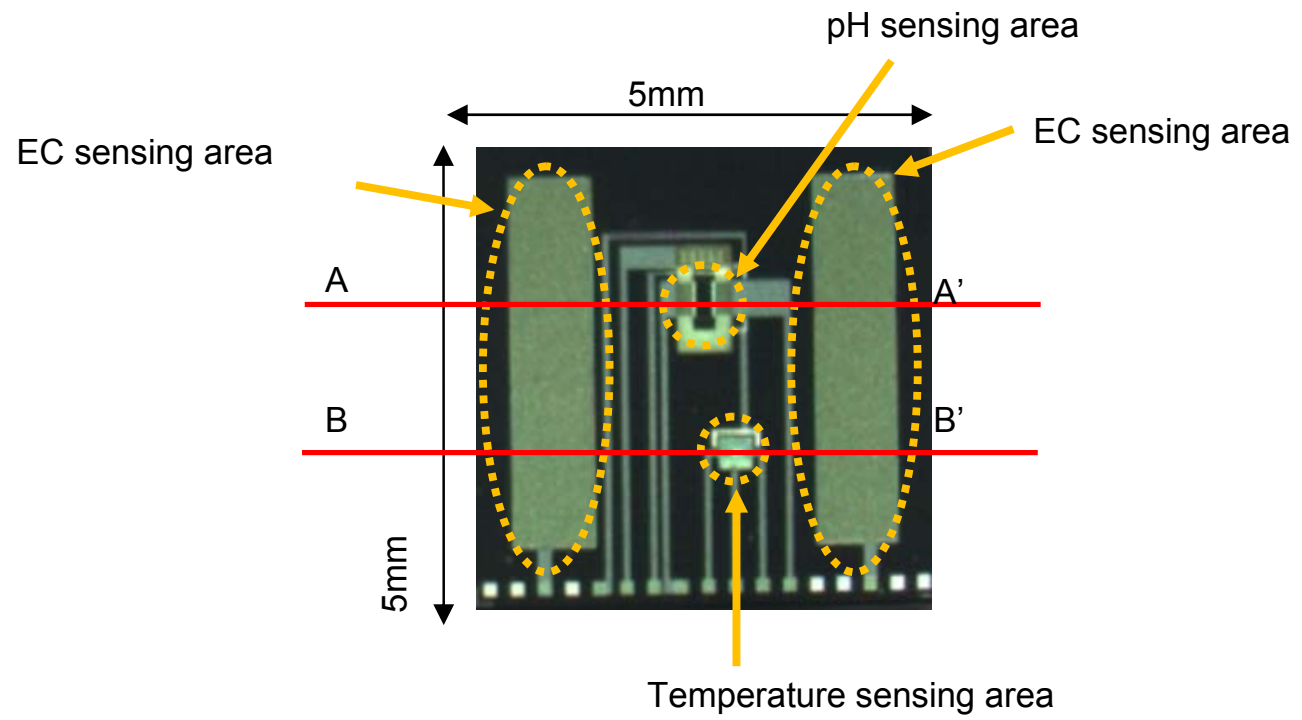


Figure 4. Schematic cross-sections through the multimodal sensor chip. (a) The $\mathrm{pH}$ and EC sensing areas through $\mathrm{A}-\mathrm{A}^{\prime}$ in Figure 3. The $\mathrm{pH}$ sensing area is between the $\mathrm{Pt}$ electrodes; (b) The temperature and EC sensing areas through B-B' in Figure 3. The temperature sensing area is also between the electrodes.

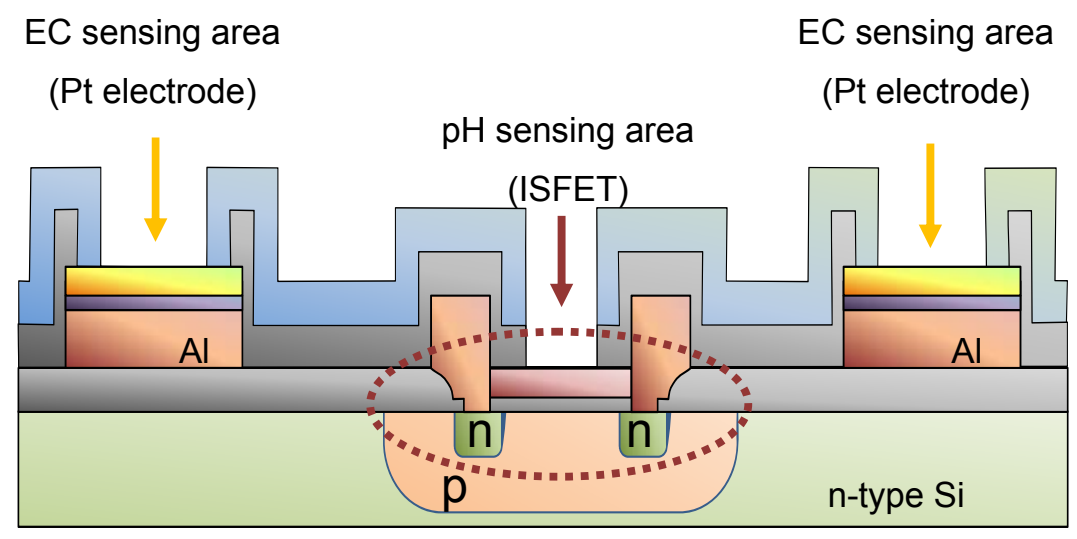

(a)

EC sensing area

EC sensing area

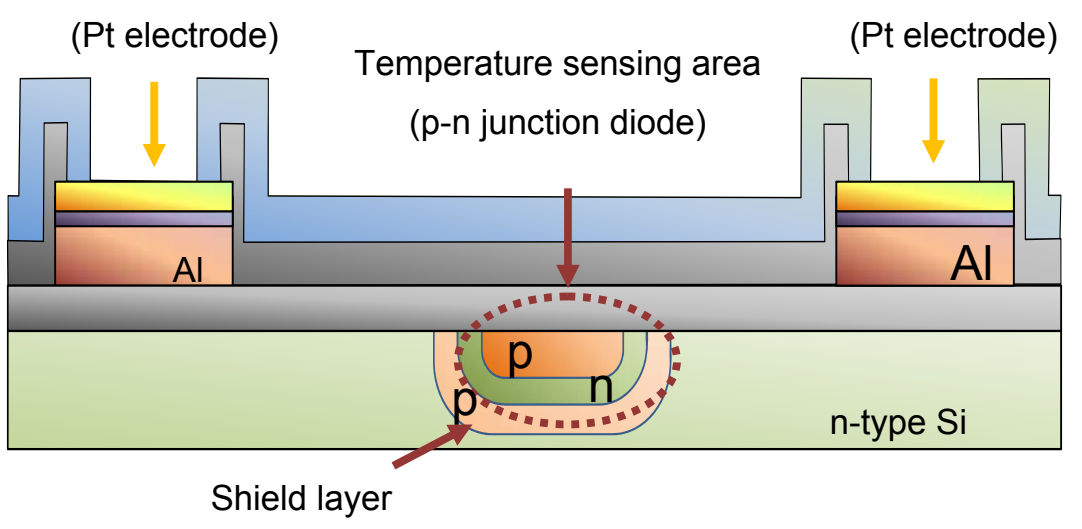

(b)

Figure 4 shows cross-sections of the structure at A-A' and B-B' in Figure 3. As seen in Figure $4(\mathrm{a})$, the $\mathrm{pH}$-sensing region of the device proposed here consists of three layers: $\mathrm{Si}_{3} \mathrm{~N}_{4}$ (ion-sensitive membrane) $/ \mathrm{SiO}_{2} / \mathrm{p}$-type $\mathrm{Si}$ substrate. The voltage potential of the $\mathrm{Si}_{3} \mathrm{~N}_{4}$ film is proportional to the $\mathrm{pH}$, and the voltage potential for values of $\mathrm{pH}$ between 1 and 9 can be measured [35]. So that the operating point was at zero volts, a depletion type ISFET was designed. The p-Well layer is connected to source electrode of ISFET for unaffected by substrate bias change and disturbance. Aluminum (Al) is used for electrical connections to the Pt electrodes of the EC sensing area. Silicon dioxide $\left(\mathrm{SiO}_{2}\right)$ is used to isolate the electrodes from the $\mathrm{Si}$ substrate. The thickness of this layer is $1 \mu \mathrm{m}$ or more, because the leakage current from the sensor to the Si substrate during operation has to be small. Figure 4(b) shows the structure of the temperature sensing area. This is a p-n junction diode in a p-type diffusion layer which was fabricated together with the ISFET using the Si LSI technology. Passivation layers of $\mathrm{SiOx}$ and $\mathrm{SiN}$ are used to isolate the temperature sensor from the solution. The temperature sensor is shielded by the p-type diffusion layer to isolate it and shield it from noise arising from changes in potential of the $\mathrm{pH}$ sensor, leakage current from the EC sensor and other external sources. The shielding layer is needed to stabilize the sensor potential for simultaneous measurements, 
because the sensitivity of the temperature sensor is only small (about $1 \mathrm{mV} /{ }^{\circ} \mathrm{C}$ ). The shielding layer is needed connected to cathode of diode for them.

\subsection{A Signal Processing Circuit Module}

For simultaneous measurements, an analog signal processing circuit using discrete components was fabricated on a PCB (Figure 5). The board includes filters (high-pass filter for the EC sensor, low-pass filter for the $\mathrm{pH}$ sensor), a power supply ( $10 \mathrm{kHz}$ sine wave for the EC sensor, DC voltages for the $\mathrm{pH}$ and temperature sensors) and amplifiers (variable gain between 5 and 50) for each sensor. Input ranges, which are between 1 and 2 volts from $\mathrm{pH}$ sensor, 100 and $100 \mathrm{k} \mathrm{ohm}$ of $\mathrm{EC}$, and 0.1 and 1 volts of temperature, can change output voltages between 0 and 2. In addition, an AC to DC converter circuit was fabricated on the board because we used multi-channel voltages recording for the real time measurements.

Figure 5. Photograph of signal processing circuit.

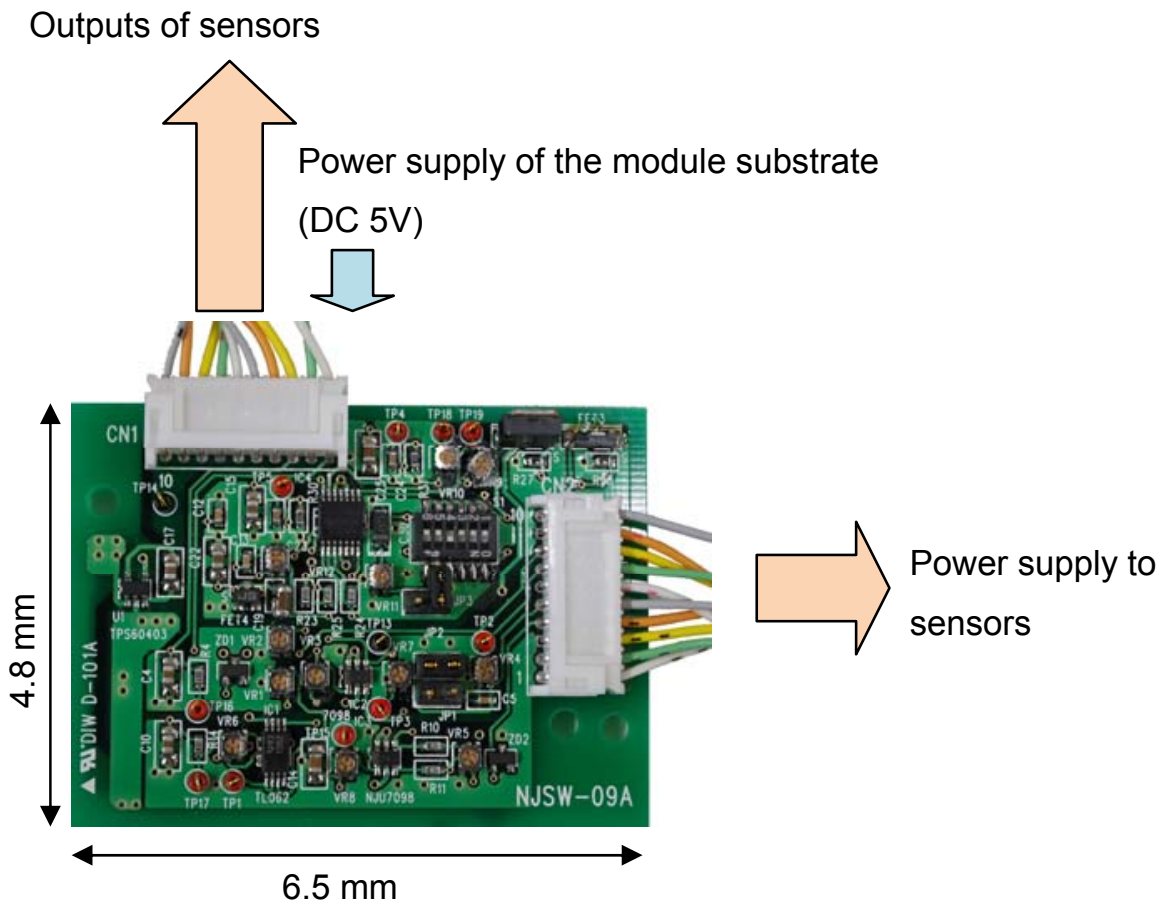

\section{Results and Discussion}

In this section we show the results of measurements made with the sensor chip. In Section 4.1, the individual characteristics of each sensor are shown to confirm the measurement ranges. In Section 4.2, simultaneous measurements of a $\mathrm{pH}$ buffer solution were made with the multimodal sensor to demonstrate the elimination of crosstalk. In Section 4.3, we describe in situ monitoring in rock wool and investigate the capability of the sensor for making measurements in a culture medium. 


\subsection{Individual Characteristics of the $p H, E C$ and Temperature Sensing Areas}

The individual characteristics of each sensing area were confirmed. In each case, measurements were made with the other sensors disconnected, for example, when operating the $\mathrm{pH}$ sensing area, no voltages were applied to the EC and temperature sensors. Therefore, the individual results shown in Figures 6 to 8 were stable and without crosstalk. Ranges, which are EC between 0.007 and $5 \mathrm{~S} / \mathrm{m}$, temperature 5 and $50{ }^{\circ} \mathrm{C}$, and $\mathrm{pH} 2$ and 9 , are almost needed in agriculture. The results of sensors show that the measurement ranges and linearity are sufficient for use in agriculture.

Figure 6. Characteristics of $\mathrm{pH}$ sensing area. The sensitivity of $43.8 \mathrm{mV} / \mathrm{pH}$ is sufficient for use as a $\mathrm{pH}$ sensor.

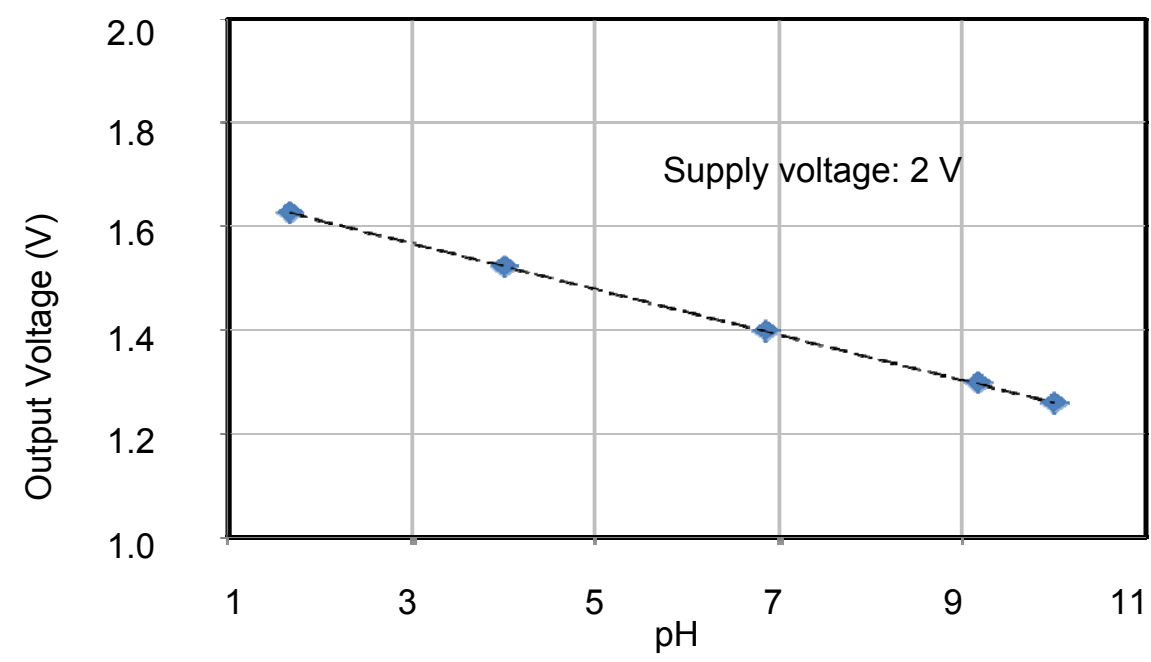

Figure 7. Characteristics of EC sensing area. The operating range is wide enough for use in agriculture.

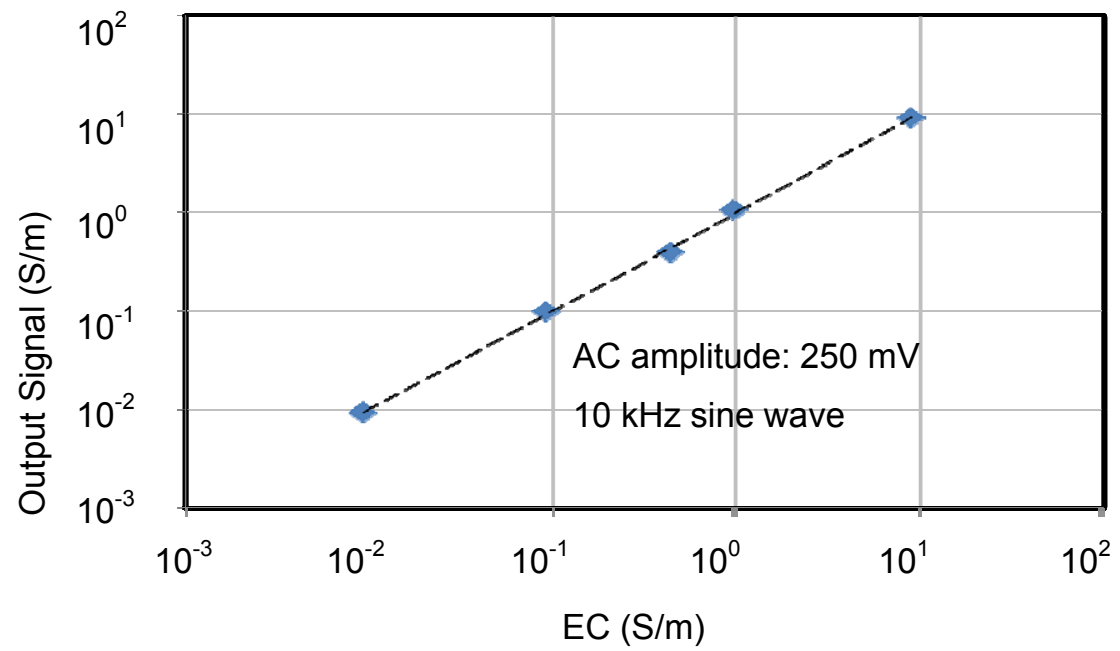


Figure 8. Characteristics of the temperature sensing area. It has a good sensitivity of $1.1 \mathrm{mV} /{ }^{\circ} \mathrm{C}$ and good linearity.

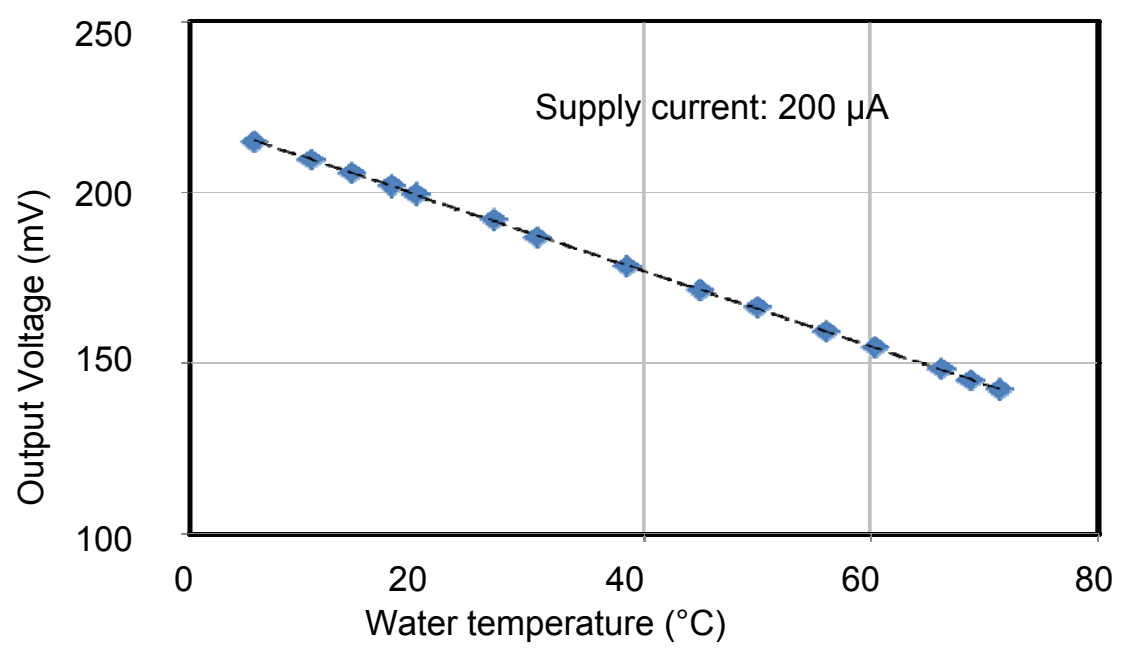

The $\mathrm{pH}$ sensor was capable of measurements between about $\mathrm{pH} 2$ and $\mathrm{pH} 10$. This it can be used to monitor almost any crop. The EC sensor had a wide measurement range from $10 \mathrm{mS} / \mathrm{m}$ (tap water) to $10 \mathrm{~S} / \mathrm{m}$ (sea water). This is sufficient for use in agriculture. It was confirmed that the temperature sensor could be used to monitor temperatures between 5 and $70{ }^{\circ} \mathrm{C}$, which is sufficient for agricultural needs. These results confirm the successful fabrication of the multimodal sensor.

Long-term stability of their sensors had been confirmed by way of experiments. EC sensor operation for almost a year and 7 months has been achieved [8]. The temperature sensor was confirmed to measure stably for a year. The $\mathrm{pH}$ measurements worked for a week. The stability of the $\mathrm{pH}$ sensor is obviously not enough to operate in agriculture. However, a study for long-term $\mathrm{pH}$ experiment has been proceeding in our group. A report of our results will be presented in the future.

\subsection{Simultaneous Measurements Using a pH Buffer Solution}

The multimodal chip and the analog processing circuit shown in Figure 5 were used to make simultaneous measurements in real time in order to check for the elimination of crosstalk between each sensor. Figure 9 shows a photograph of the measurement set up with a reference electrode and $\mathrm{pH} 4.01$ buffer solution. The $\mathrm{pH}$ sensor electrode was used to maintain the voltage of the solution at zero. One characteristic of the buffer solution is that there is no change in $\mathrm{pH}$ when the solution is diluted. In this experiment, it was shown that the $\mathrm{pH}$ did not change, but the EC and temperature measurements changed when the buffer solution was diluted with tap water.

Figure 10 shows the results of measurements of $\mathrm{pH}, \mathrm{EC}$, and temperature. Initially, the chip was dried at $26^{\circ} \mathrm{C}$, then $100 \mu \mathrm{L}$ of $\mathrm{pH} 4.01$ buffer solution was introduced between the multi-modal sensor and the reference electrode at $20^{\circ} \mathrm{C}$. After $3.6 \mathrm{~min}$, the measurements recorded by the chip were $\mathrm{pH}$ 4.0, EC $0.82 \mathrm{~S} / \mathrm{m}$ and temperature $19.8{ }^{\circ} \mathrm{C}$. At $3.6 \mathrm{~min}$, hot tap water (volume: $50 \mu \mathrm{L}, \mathrm{pH}: 7$, EC: $7 \mathrm{mS} / \mathrm{m}$, temperature: $27.6^{\circ} \mathrm{C}$ ) was added to the solution. Following this, the EC measurement fell to $0.46 \mathrm{~S} / \mathrm{m}$ and the temperature rose to $24.4^{\circ} \mathrm{C}$. However, the $\mathrm{pH}$ remained unchanged. After $7.4 \mathrm{~min}$, cold tap water (volume: $30 \mu \mathrm{L}$, EC: $7 \mathrm{~S} / \mathrm{m}$, temperature: $13.2{ }^{\circ} \mathrm{C}$ ) was added. The EC measurement 
changed again to $0.29 \mathrm{~S} / \mathrm{m}$, and the temperature fell to $15.8^{\circ} \mathrm{C}$. As before, the $\mathrm{pH}$ remained the same. These results show that there was no crosstalk between the sensors and correct sensing operation was achieved. When the $\mathrm{pH} 4.0$ solution was diluted by tap water, the EC and the temperature changed, but the $\mathrm{pH}$ remained unchanged. These results are characteristic of the buffer solution. Successful real time and simultaneous measurements were made using the multi-modal chip.

Figure 9. Photograph of the measurement set up for the multimodal sensor chip.

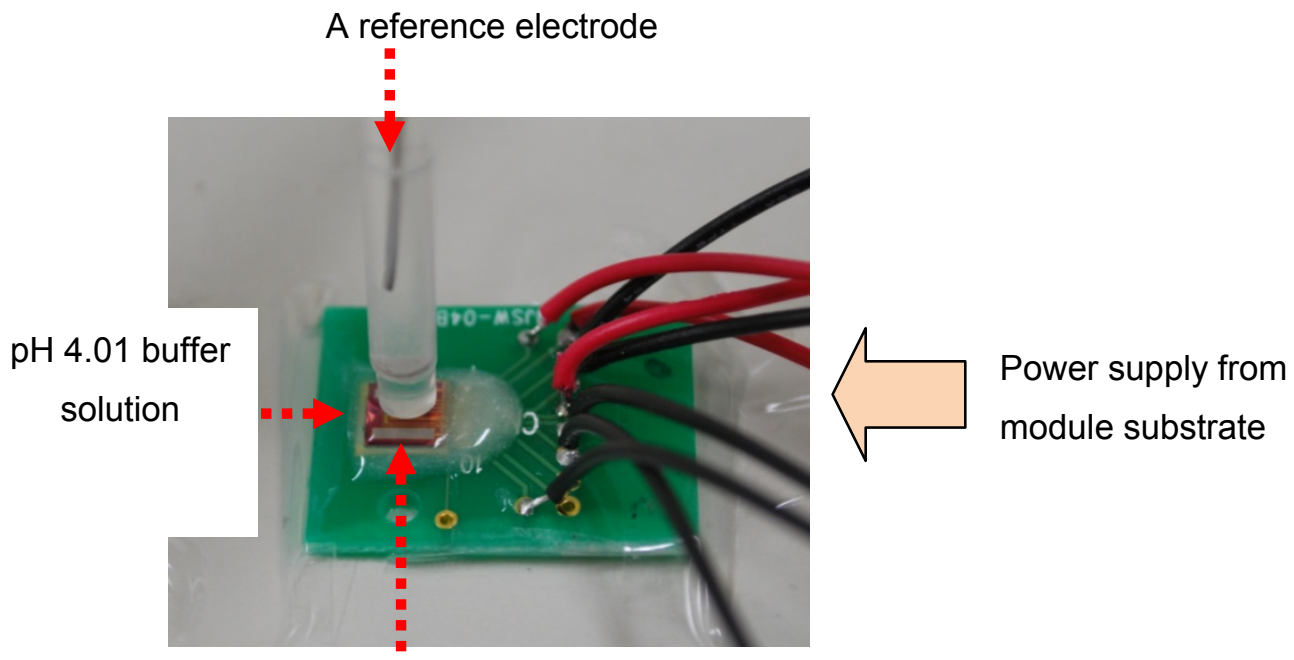

A multi-modal sensor chip

Figure 10. Results of measurements using the multimode sensor.

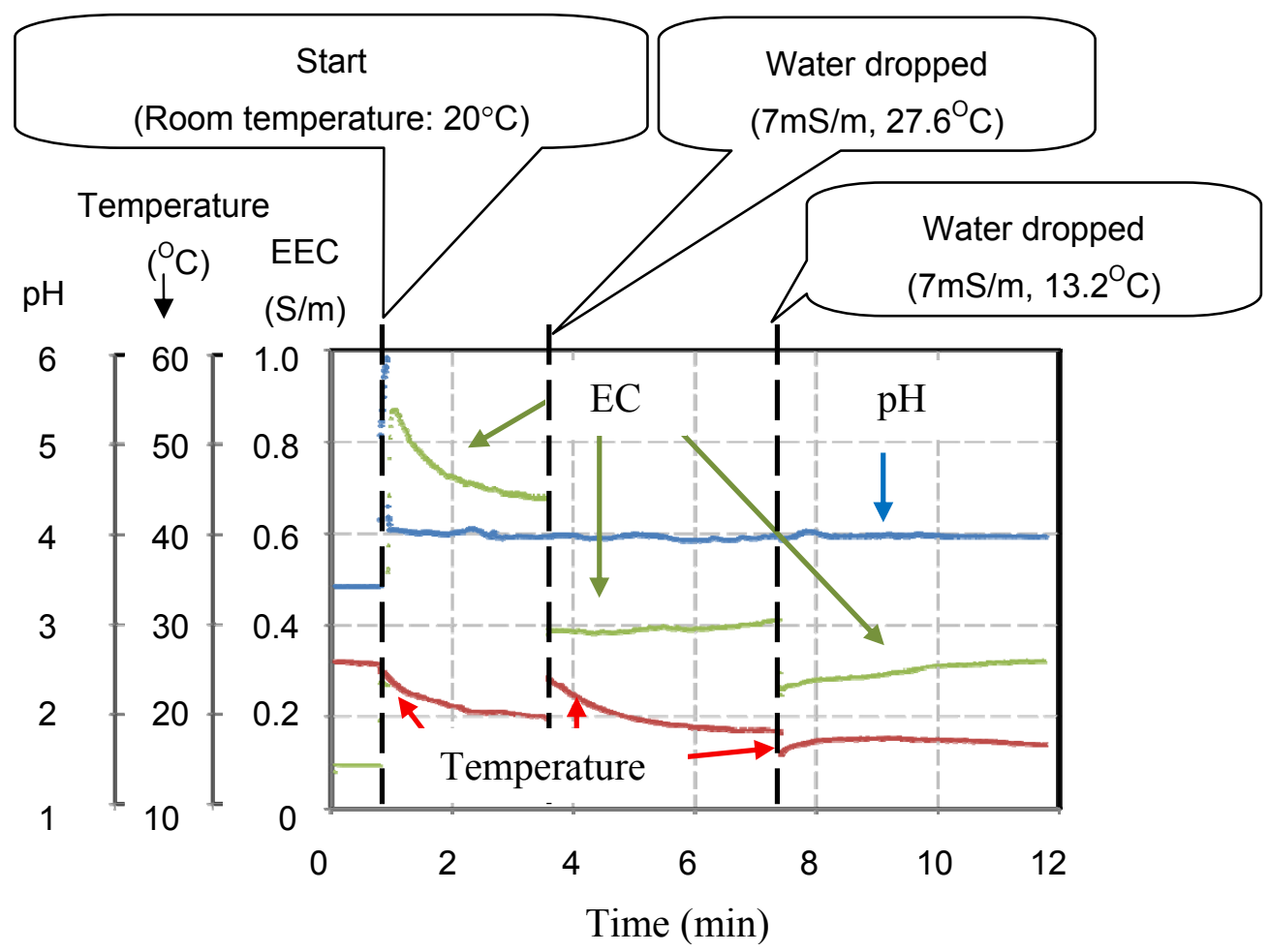




\subsection{Simultaneous Measurements in Rock Wool}

The multimodal sensor was inserted into rock wool to conduct in situ simultaneous real time monitoring of three important quantities used in precision agriculture. Figure 11 shows a photograph of the sensor chip and the experiment. A nutrient solution used in agriculture was diluted by $1 \%$. Plenty of the solution was added to the rock wool initially.

The position of the reference electrode was checked for its impact on the $\mathrm{pH}$ measurement. When the distance between the sensor and the electrode was changed from $1 \mathrm{~cm}$ to $12 \mathrm{~cm}$, the stability of the $\mathrm{pH}$ measurement was about $\mathrm{pH} 0.02$ which is sufficient for agricultural purposes. Therefore, the measurement was not limited by the position of the electrode. Additionally, for removal reference electrode, reference field effect transistor (REFET) [36] and etc. had been studied in other groups. The reference electrode will be no need to operate in $\mathrm{pH}$ measurements.

Figure 11. Photograph of the sensor chip and the experiment. (a) The $5 \mathrm{~mm} \times 5 \mathrm{~mm}$ sensor chip bonded and electrically-wired to a PCB substrate. The connections between the chip and the PCB, and between the PCB and the lead wires are shielded by epoxy resin and adhesive bonds; (b) The sensor and the reference electrode are inserted in the rock wool. The rock wool includes a nutrient solution diluted by $1 \%$.

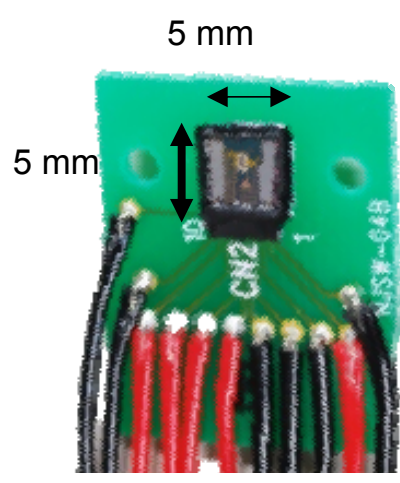

(a)

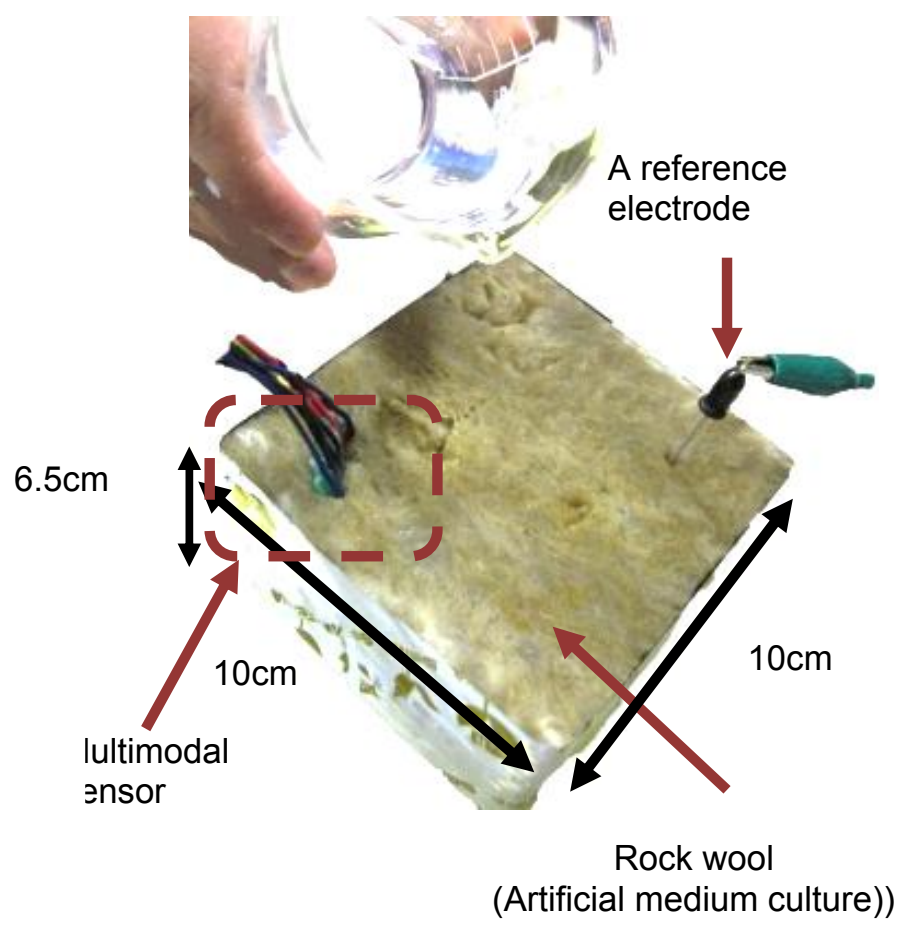

(b)

Figure 12 shows the experimental results of the in situ measurements. Table 2 shows the data for the results shown in Figure 12. Various $25 \mathrm{~mL}$ solutions were dropped onto the rock wool. First, a $\mathrm{pH}$ 6.86 buffer solution diluted by $22 \%$, in which $\mathrm{pH}$ buffering effect of the solution becomes weak, was added at points $\mathrm{A}$ and $\mathrm{B}$. The $\mathrm{pH}$ changes from $\mathrm{pH} 6.8$ to 7.39 at point $\mathrm{A}$ and remains at $\mathrm{pH} 7.39$ at point $\mathrm{B}$. When a warm solution was added at point $\mathrm{C}$, the temperature changed from 26.5 to $30.7^{\circ} \mathrm{C}$. At point $\mathrm{E}$, a $\mathrm{pH} 4.01$ buffer solution without dilution was added. The $\mathrm{pH}$ sensor output changed to 
4.38, and the temperature output changed to $28.2{ }^{\circ} \mathrm{C}$ after adding the colder solution. The EC characteristics of the solution rise from $0.115 \mathrm{~S} / \mathrm{m}$ at A to $0.396 \mathrm{~S} / \mathrm{m}$ at E. At $\mathrm{F}$, a $\mathrm{pH} 9.18$ buffer solution without dilution was added. The $\mathrm{pH}$ output changed to 9.39, and the EC output changed from 0.396 to $0.288 \mathrm{~S} / \mathrm{m}$, which is smaller than the $\mathrm{EC}$ at $\mathrm{pH}$ 4.01. From points $\mathrm{G}$ to $\mathrm{K}$, tap water was added. As the solution in the rock wool is gradually diluted, the EC output decreases and the $\mathrm{pH}$ output moves towards a neutral $\mathrm{pH}$ value. The reactions of the sensors to the added solutions are shown in Table 2 . These results show significant changes in sensor output in response to the added solutions. In actual fact, the sensor outputs were not completely in accord with the characteristics of the mixed solutions included in the rock wool. However, the results show that the sensor is capable of continual surveillance of a culture medium in real time, and in situ monitoring is important to gain an understanding of the optimum conditions. In this experiment, the sensor was inserted near the surface of the rock wool. Therefore, quick responses to the added solutions were obtained. If the sensor was inserted at the base in an actual cultivation environment, the information gained would be of unused nutrients.

Figure 12. Results of experimental in situ measurements. Various $25 \mathrm{~mL}$ solutions were dropped onto the rock wool.

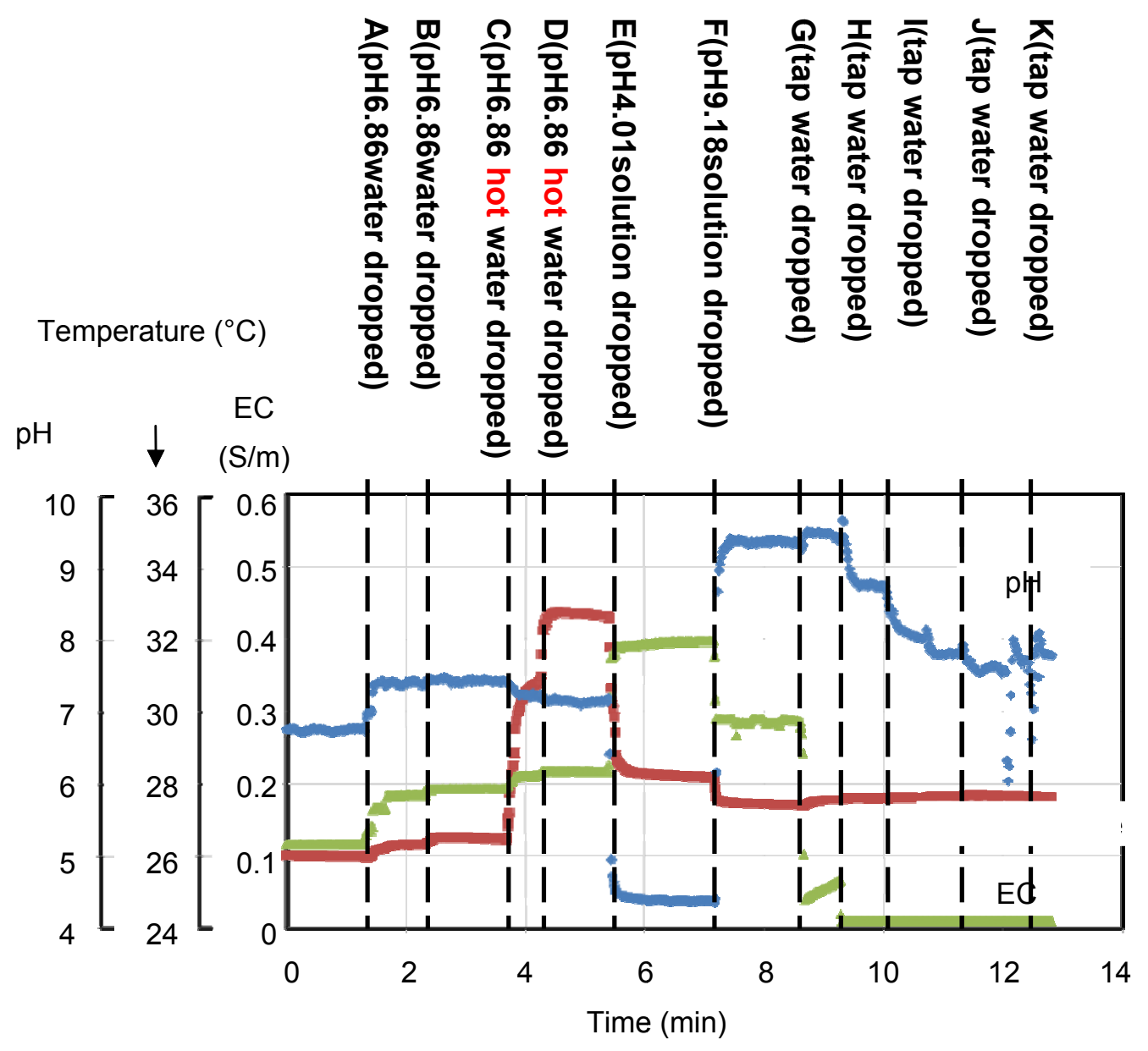


Table 2. The data in Figure 12 is shown in the table in order to compare the reaction of the sensors to the added water. The initial nutrient solution was diluted to a density of $1 \%, \mathrm{~A}$, $\mathrm{B}, \mathrm{C}$ and D were pH6.86 buffer solutions diluted to a density $22 \%$, E was a $\mathrm{pH} 4.01$ buffer solution without dilution, $\mathrm{F}$ was a $\mathrm{pH} 9.18$ buffer solution without dilution, and $\mathrm{G}$ to $\mathrm{K}$ were tap water.

\begin{tabular}{ccccccc}
\hline \multirow{2}{*}{ Point } & \multicolumn{3}{c}{ Characteristics of Solutions } & \multicolumn{3}{c}{ Sensor Outputs } \\
\cline { 2 - 7 } & $\mathbf{E C}(\mathbf{S} / \mathbf{m})$ & Temperature $\left({ }^{\circ} \mathbf{C}\right)$ & $\mathbf{p H}$ & $\mathbf{E C}(\mathbf{S} / \mathbf{m})$ & Temperature $\left({ }^{\circ} \mathbf{C}\right)$ & $\mathbf{p H}$ \\
\hline Initial & 0.120 & 26.6 & 6.10 & 0.115 & 26.0 & 6.8 \\
A & 0.190 & 27.1 & 7.05 & 0.182 & 26.3 & 7.39 \\
B & Same as above & Same as above & Same as above & 0.191 & 26.5 & 7.39 \\
C & 0.190 & 35.6 & 7.05 & 0.203 & 30.7 & 7.28 \\
D & Same as above & Same as above & Same as above & 0.217 & 32.7 & 7.08 \\
E & 0.502 & 25.5 & 4.01 & 0.379 & 28.2 & 4.38 \\
F & 0.186 & 25.7 & 9.18 & 0.288 & 27.4 & 9.39 \\
G & 0.00808 & 27.8 & 8.03 & 0.0509 & 27.8 & 9.45 \\
H & Same as above & Same as above & Same as above & 0.0102 & 27.6 & 8.76 \\
I & Same as above & Same as above & Same as above & 0.0102 & 27.6 & 7.78 \\
J & Same as above & Same as above & Same as above & 0.0103 & 27.7 & 7.61 \\
K & Same as above & Same as above & Same as above & 0.0102 & 27.6 & 7.80 \\
\hline
\end{tabular}

Figure 13 is shows to compare results in sensor outputs of Table 2 . If the point A of Table 2 is ideal, other points which are hotter point, acidity point, alkaline area and dilute area need adjustment of conditions. When $\mathrm{E}$ of alkaline area was diluted for toward neutral $\mathrm{pH}$, the $\mathrm{pH}$ achieved it in exchange for decrement of EC in line 1 which were $\mathrm{E}$ though $\mathrm{K}$. Their speculations showed of efficacy of multimodal sensor. Additionally, agricultural workers will be able to visualize of condition in medium culture by using the sensor.

Figure 13. Comparing results of $\mathrm{pH}, \mathrm{EC}$ and temperature in sensor outputs of Table 2 is shown. The size of circle was varied by temperature value, for example, smallest circle is $26.0^{\circ} \mathrm{C}$, and largest circle is $32.7^{\circ} \mathrm{C}$.

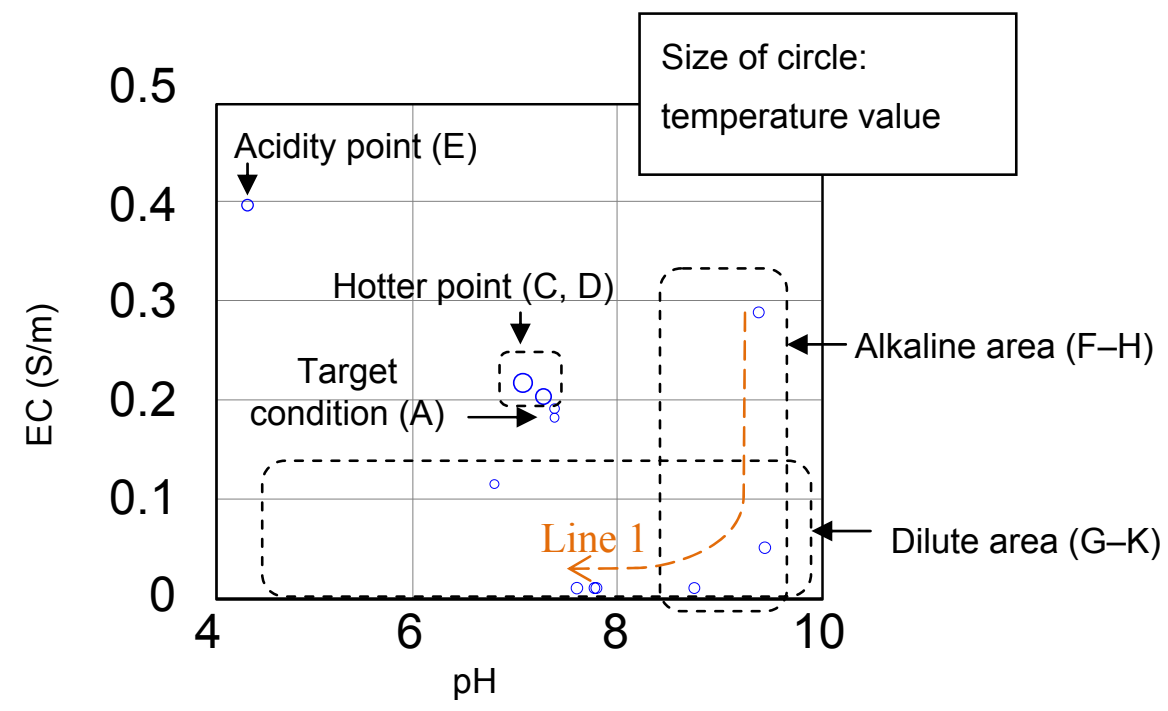




\section{Conclusions}

An integrated multimode sensor for simultaneous measurements of the $\mathrm{pH}, \mathrm{EC}$ and temperature of a conducting solution was proposed. Crosstalk through the solution and the chip substrate makes it difficult to make simultaneous independent localized measurements for different operating methods of the sensors. However, in situ measurements in non-uniform media are needed in order to do a proper analysis. The sensor structure and operating conditions were designed to solve this problem. We successfully fabricated multimodal sensors using a Si LSI process. We also made a signal processing circuit using discrete components. Simultaneous measurements of $\mathrm{pH}, \mathrm{EC}$ and temperature in a $\mathrm{pH} 4.01$ buffer solution and in rock wool were demonstrated. The experimental results showed that the sensor could be used to simultaneously measure $\mathrm{pH}, \mathrm{EC}$ and temperature in the same area without limitation. A usable sensor for precision control in agriculture was achieved.

\section{Acknowledgments}

This work was partially supported by the Global COE Program "Frontiers of Intelligent Sensing" from the Ministry of Education, Culture, Sports, Science and Technology, Coalition Research Program for Agriculture and Engineering, the National Institute of Vegetable and Tea Science (NIVTS) in Taketoyo and Advanced Domestic Animal Management System for Practical Application Program.

\section{References}

1. Slade, L.; Levine, H.; Reid, D.S. Beyond water activity: Recent Advances based on an alternative approach to the assessment of food quality and safety. Crit. Rev. Food Sci. Nutr. 1991, 30, 115-360.

2. Bánáti, D. The EU and candidate countries: How to cope with food safety policies? Food Control 2003, 14, 89-93.

3. Miraglia, M.; Berdal, K.G.; Brera, C.; Corbisier, P.; Holst-Jensen, A.; Kok, E.J.; Marvin, H.J.P.; Schimmel, H.; Rentsch, J.; van Rie, J.P.P.F.; Zagon, J. Detection and traceability of genetically modified organisms in the food production chain. Food Chem. Toxicol. 2004, 42, 1157-1180.

4. Wanga, N.; Zhang, N.; Wang, M. Wireless sensors in agriculture and food industry-Recent development and future perspective. Comput. Electron. Agric. 2006, 50, 1-14.

5. Satow, T.; Matsuda, K.; Ming, S.B.; Hironaka, K.; Tan, D.L.S. Development of Laser Crop Row Sensor for Automatic Guidance System of Implements. In Proceedings of the American Society of Agricultural and Biological Engineers, Kyouto, Japan, 7-8 October 2004.

6. Warrick, A.W.; Gardner, W.R.; Wang, M. Crop yield as affected by spatial variations of soil and irrigation. Water Resour. Res. 1983, 19, 181-186.

7. Hoag, D.L. The intertemporal impact of soil erosion on non-uniform soil profiles: A new direction in analyzing erosion impacts. Agric. Syst. 1998, 56, 415-429.

8. Kawashima, K.; Futagawa, M.; Ban, Y.; Asano, Y.; Sawada, K. Measurement of electrical conductivity into tomato cultivation beds using small insertion type electrical conductivity sensor designed for agriculture. IEE J. Trans. Sens. Micromach. 2011, 131, 211-217.

9. Ryan, P.R.; Delhaize, E. Functionand mechanism of organic anion exudation from plant roots. Annu. Rev. Plant Physiol. Plant Mol. Biol. 2001, 52, 527-560. 
10. Savvas, D.; Konstantinos, A. Automated management of nutrient solutions based on target electrical conductivity, $\mathrm{pH}$, and nutrient concentration ratios. J. Plant Nutr. 1999, 22, 1415-1432.

11. Massa, D.; Incrocci, L.; Maggini, R.; Bibbiani, C.; Carmassi, G.; Malorgio, F.; Pardossi, A. Simulation of crop water and mineral relations in greenhouse soilless culture. Environ. Model. Softw. 2011, 26, 711-722.

12. Lucas, R.E.; Davis, J.F. Relationship between $\mathrm{pH}$ values of organic soils and availability of 12 plant nutrients. Soil Sci. 1961, 92, 177-182.

13. Tyler, G.; Olsson, T. Concentrations of 60 elements in the soil solution asrelated to the soil acidity. Eur. J. Soil Sci. 2001, 52, 151-165.

14. Silber, A.; Bar-Yosef, B.; Levkovitch, I.; Kautzky, L.; Minz, D. Kinetics and mechanisms of pH-dependent $\mathrm{Mn}(\mathrm{II})$ reactions inplant-growth medium. Soil Biol. Biochem. 2008, 40, 2787-2795.

15. Borgognone, D.; Colla, G.; Rouphael, Y.; Cardarelli, M.; Rea, E.; Schwarzd, D. Effect of nitrogen form and nutrient solution $\mathrm{pH}$ on growth and mineralcomposition of self-grafted and grafted tomatoes. Sci. Hort. 2012, doi:10.1016/j.scienta.2012.02.012.

16. Friedman, S.P. Soil properties influencing apparent electrical conductivity. Comput. Electron. Agric. 2005, 46, 45-70.

17. Massa, D.; Incrocci, L.; Maggini, R.; Carmassi, G.; Campiotti, C.A.; Pardossi, A. Strategies to decrease water drainage and nitrate emission from soilless cultures of greenhouse tomato. Agric. Water Manag. 2010, 97, 971-980.

18. Reich, P.B.; Olwksyn, J. Global patterns of plant leaf $\mathrm{N}$ and $\mathrm{P}$ in relation to temperature and latitude. Proc. Natl. Acad. Sci. USA 2004, 101, 11001-11006.

19. Abbas Al-ani, M.K.; Hay, R.K.M. The influence of growing temperature on the growth and morphology of cereal seedling root systems. J. Exp. Bot. 1983, 34, 1720-1730.

20. Criddle, R.S.; Smith, B.N.; Hansen, L.D. A respiration based description of plant growth rate responses to temperature. Planta 1997, 201, 441-445.

21. Bristow, K.L.; Kluitenberg, G.J.; Goding C.J.; Fitzgerald, T.S. A small multi-needle probe for measuring soil thermal properties, water content and electrical conductivity. Comput. Electron. Agric. 2001, 31, 265-280.

22. Zeng, Q.; Sun, Y.; Lammers, P.S.; Ma, D.; Lin, J.; Hueging, H. Improvement of a dual-sensor horizontal penetrometer by incorporating an EC sensor. Comput. Electron. Agric. 2008, 64, 333-337.

23. Artigas, J.; Beltran, A.; Jime'nez, C.; Baldi, A.; Mas, R.; Dominguez, C.; Alonso, J. Application of ion sensitive field effect transistor based sensors to soil analysis. Comput. Electron. Agric. 2001, 31, 281-293.

24. Futagawa, M.; Iwasaki, T.; Takao, H.; Ishida, M.; Sawada, K. Miniaturization of electrical conductivity sensors for a multimodal smart microchip. Jpn. J. Appl. Phys. 2009, 48, 04C184:1-04C184:4.

25. Futagawa, M.; Hussain, M.D.I.; Kamado, K.; Dasai, F.; Ishida, M.; Sawada, K. An integrated multimodal sensor for the on-site monitoring of the water content and nutrient concentration of soil by measuring the phase and electrical conductivity. Sens. Trans. J. 2012, 14-1, 160-173. 
26. Futagawa, M.; Iwasaki, T.; Ishida, M.; Kamado, K.; Ishida, M.; Sawada, K. A real-time monitoring system using a multimodal sensor with an electrical conductivity sensor and a temperature sensor for cow health control. Jpn. J. Appl. Phys. 2010, 49, 04DL12:1-04DL12:4.

27. Futagawa, M.; Ishida, M.; Ishida, M.; Sawada, K. Study of a wireless multimodal sensing system integrated with an electrical conductivity sensor and a temperature sensor for the health control of cows. IEEJ Trans. Electr. Electron. Eng. 2011, 6, 93-96.

28. De Rooij, N.F.; Bergveld, P. The influence of the $\mathrm{pH}$ on the electrolyte-SiO $\mathrm{S}_{2}-\mathrm{Si}$ system studied by ion-sensitive FET measurements and quasi-static C-V measurements. Thin Solid Films 1980, 71, $327-331$.

29. Lue, C.-E.; Lai, C.-S.; Wang, I.-S.; Yang, C.-M. Sensitivity of trapping effect on Si3N4 sensing membrane for ion sensitive field effect transistor/reference field effect transistor pair application. Sens. Lett. 2010, 8, 725-729.

30. Hizawa, T.; Sawada, K.; Takao, H.; Ishida, M. Fabrication of a two-dimensional pH image sensor using a charge transfer technique. Sens. Actuators B 2006, 117, 509-515.

31. Levine, S.; Smith, A.L. Theory of the differential capacity of the oxide/aqueous electrolyte interface. Discuss. Faraday Soc. 1971, 52, 290-301.

32. Matsuo, T.; Esashi, M. Methods of ISFET fabrication. Sens. Actuators 1981, 1, 77-96.

33. Bard, A.J.; Faulkner, L.R. Estimated Potential Ranges in Aqueous and Nonaqueous Solutions. In Electrochmical Methods, Fundamentals and Applications; John Wiley \& Sons Inc.: New York, NY, USA, 1980.

34. Sze, S.M. p-n Junction Diode. In Physics of Semiconductor Devices, 2nd ed.; John Wiley \& Sons Inc.: New York, NY, USA, 1981; p. 92.

35. Niu, M.N.; Ding, X.F.; Tong, Q.Y. Effect of two types of surface sites on the characteristics of $\mathrm{Si}_{3} \mathrm{~N}_{4}$-gate pH-ISFETs. Sens. Actuators B 1996, 37, 13-17.

36. Errachid, A.; Bausells, J.; Jaffrezic-Renault, N. A simple REFET for pH detection in differential mode. Sens. Actuators B 1999, 60, 43-48.

(C) 2012 by the authors; licensee MDPI, Basel, Switzerland. This article is an open access article distributed under the terms and conditions of the Creative Commons Attribution license (http://creativecommons.org/licenses/by/3.0/). 